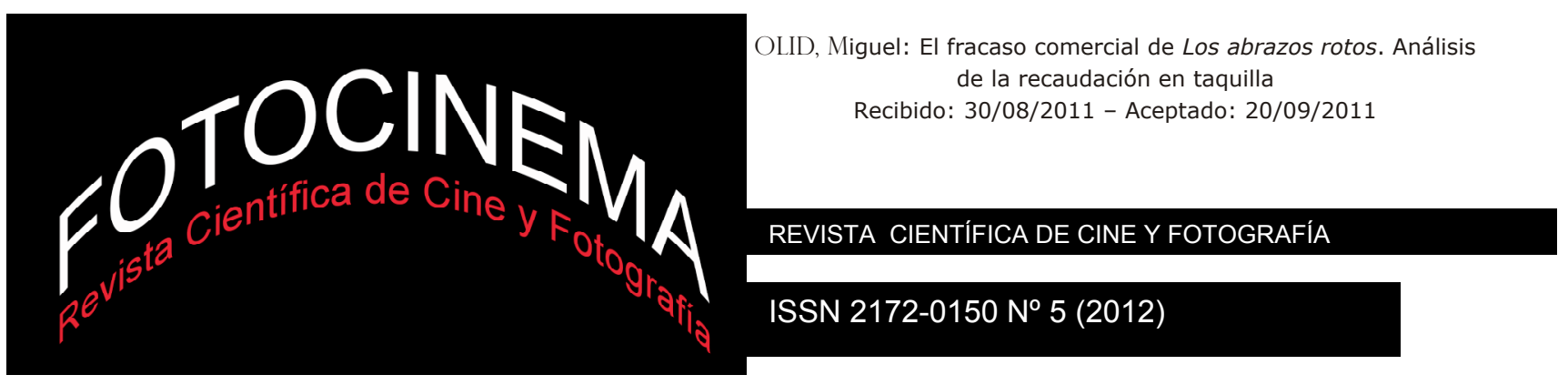

\title{
EL FRACASO COMERCIAL DE LOS ABRAZOS ROTOS. ANÁLISIS DE LA RECAUDACIÓN EN TAQUILLA
}

\author{
THE FINANCIAL FAIL OF LOS ABRAZOS ROTOS (BROKEN \\ EMBRACES). ANALYSIS OF THE BOX OFFICE
}

\section{Miguel Olid}

\section{Resumen:}

Los abrazos rotos fue un fracaso comercial. Después del éxito de Volver, Los abrazos rotos consiguió menos de la mitad de la recaudación y casi un tercio de espectadores. También obtuvo peores resultados que el resto de las películas dirigidas por Almodóvar en este siglo. El fracaso no sólo sucedió en España, sino también en Francia, Estados Unidos y fue, de las cinco últimas, la que en menos países se ha estrenado. ¿Cuáles pudieron ser los motivos de este fracaso? En España coincidió en cartel con Gran Torino de Clint Eastwood, con un público similar y también adulto. Malas críticas en su estreno, una agria polémica con el principal crítico de cine, y una excesiva duración (se trata de la más larga en la obra de Almodóvar) pudieron influir en estos malos resultados económicos.

\begin{abstract}
:
Los abrazos rotos (Broken embraces) was a financial failed movie. After the box office success of Volver, Los abrazos rotos got less of half of the total gross in Spain and almost the third of its audience. This movie got the worse box office tham the Almodovar's movies released in this century. The fail was also in France, the United States and was, among the five latest movies, the less sale around the world.

Which reasons could cause this financial fail? The release date in Spain was the same day of Gran Torino, directed by Clint Eastwood, with a similar and also adult audience. The movie had very bad reviews, Almodóvar and the main spanish critic had a bitter controversial and an over length running time could cause this financial fail.
\end{abstract}

\section{Palabras clave:}

Almodóvar; taquilla; crítica de cine; fracaso; éxito.

\section{Key words:}

Almodóvar; box office; film review; financial fail; success. 


\section{Introducción}

Los abrazos rotos (Broken embraces en su título en inglés), de Pedro Almodóvar, se estrenó el 18 de marzo de 2009, justo un lustro después de La mala educación. En su lanzamiento se proyectó en 246 salas de toda España, donde permaneció en cartel durante 16 semanas. Según datos del Ministerio de Cultura obtuvo una recaudación total de algo más de cuatro millones de euros $(4.172 .843,54)$ y fue vista por 696.622 espectadores. Esto la convirtió en la novena producción española más taquillera de 2009, una posición inaudita para una película de Almodóvar (al menos en las estrenadas el presente siglo; Hable con ella, La mala educación y La piel desnuda se situaron en $4^{\circ}$ lugar mientras que Volver fue la $2^{\circ}$, tras Alatriste). Además, ese año, entre las ocho que precedían Los abrazos rotos figuraban títulos como Fuga de cerebros, Spanish movie y Mentiras y gordas.

\section{Fracaso comercial en España}

Se había despertado mucha expectación con Los abrazos rotos, tras el gran éxito que logró con Volver, en la que Almodóvar regresaba a sus raíces y en la que se reencontraba con su antigua actriz fetiche, Carmen Maura, pero los resultados, comparados con el resto de las películas de Almodóvar estrenadas en los primeros años de este siglo, fueron decepcionantes.

La notable suma de premios obtenidos por Volver, la repercusión mundial que alcanzó y, especialmente, los excelentes resultados en taquilla de este filme propiciaron que Pedro Almodóvar pudiera contar con el doble de presupuesto para su siguiente producción, pasando de los siete millones y medio de euros a los quince de Los abrazos rotos.

Sin embargo, como se puede apreciar en el cuadro $\mathrm{n}^{0} 1$, el rendimiento económico de este filme no fue parejo con la duplicación del presupuesto. Así, de entrada, a pesar de contar con un mayor número de copias en su lanzamiento (246 frente a las 228 de Volver) la recaudación en el primer fin de semana fue prácticamente la mitad respecto al título precedente. La diferencia en el rendimiento entre ambos títulos creció notablemente en los ingresos totales que consiguió cada una y aumentó aún más si tomamos como referencia el número de españoles que acudieron a verla al cine, ya que casi uno de cada tres 
espectadores de Volver compró una entrada de Los abrazos rotos. Similar proporción también se puede apreciar al analizar el rendimiento medio de cada copia en ambos títulos.

Cuadro $n^{0} 1$

\section{ANÁLISIS COMPARATIVO RECAUDACIÓN EN TAQUILLA ESPAÑA VOLVER / LOS ABRAZOS ROTOS}

\section{TITLO}

TÍTULO

Fecha de estreno en España

Número de salas en estreno en España

Presupuesto

Recaudación primer fin de semana España

Recaudación total en España

Rendimiento por copia

Número de espectadores total en España

Datos del Ministerio de Cultura
VOLVER

LOS ABRAZOS ROTOS

$18 / 03 / 2009$

246

$€ 15.000 .000$

\begin{tabular}{c|c}
$€ 7.500 .000$ & $€ 15.000 .000$ \\
$€ 1.875 .000,00$ & $€ 978.046,00$ \\
$€ 10.242 .587,56$ & $€ 4.172 .843,54$ \\
$€ 44.924$ & $€ 16.963$ \\
\hline 1.930 .895 & 696.622 \\
\hline
\end{tabular}

Podría argumentarse que la comparación con Volver no es del todo justa por la extraordinaria repercusión que logró este filme de modo que incluimos un segundo cuadro donde se pueden comparar los resultados de taquilla así como número de espectadores con la película que precedió a Volver, La mala educación. Este título partió con dos dificultades que lastraban de antemano su explotación comercial. El primer factor era intrínseco y se encontraba en el propio planteamiento argumental de la película. Al contar una historia de abusos sexuales en un colegio católico durante el régimen franquista, pudo provocar el rechazo de un determinado sector del público potencial descontento con el tratamiento que podía dar a este tema. Independientemente de este elemento, más subjetivo y difícil de cuantificar en una determinada reducción de espectadores, La mala educación sí contó con un obstáculo que dificultó su explotación comercial y que bien pudo condicionar su rendimiento: el conflicto entre la distribuidora Warner (la misma de todas sus últimas películas) y la cadena de cines Renoir, que provocó la retirada de la película de una docena de 
cines en Madrid (sólo de esta capital salieron siete copias), Barcelona, Zaragoza, Palma de Mallorca y Cuenca. Este conflicto, recogido ampliamente por la prensa nacional, fue protagonizado por Enrique González Macho (actual presidente de la Academia de las Artes y las Ciencias Cinematográficas de España), como propietario de dicha cadena de cines. González Macho retiró no sólo este título sino también otras copias del catálogo de Warner como Mystic River, de Clint Eastwood, en protesta por lo que consideraba un acto de deslealtad empresarial de Warner.

\begin{tabular}{|c|c|c|}
\hline \multicolumn{3}{|l|}{ Cuadro $\mathrm{n}^{\mathrm{O}} 2$} \\
\hline \multicolumn{3}{|c|}{$\begin{array}{c}\text { ANÁLISIS COMPARATIVO } \\
\text { RECAUDACIÓN EN TAQUILLA ESPAÑA } \\
\text { I.A MAT.A FIDITCACIÓN / I OS ARRATIS ROTOS }\end{array}$} \\
\hline TÍTULO & LA MALA EDUCACIÓN & LOS ABRAZOS ROTOS \\
\hline Fecha de estreno en España & $18 / 03 / 2004$ & $18 / 03 / 2009$ \\
\hline Número de salas en estreno en España & 158 & 246 \\
\hline Presupuesto & $€ 5.000 .000$ & $€ 15.000 .000$ \\
\hline Recaudación primer fin de semana España & $€ 1.195 .000,00$ & $€$ 978.046,00 \\
\hline Recaudación total en España & $€ 6.110 .253,78$ & $€ 4.172 .843,54$ \\
\hline Rendimiento por copia & $€ 38.672$ & $€ 16.963$ \\
\hline Número de espectadores total en España & 1.241 .637 & 696.622 \\
\hline
\end{tabular}

Este conflicto no fue el causante de que sólo se estrenara en poco más de centenar y medio de pantallas, una cifra muy inferior en una película de Almodóvar (su último trabajo, La piel que habito, llegó a 287 salas). Sin embargo, a pesar de que Los abrazos rotos tuvo un 55\% más de salas que La mala educación (y a pesar de triplicar su presupuesto e indirectamente la partida destinada a publicidad y marketing), ésta logró más de 200.00o euros de recaudación en el primer fin de semana y casi dos millones más de euros en la recaudación total en salas. Dada la notable diferencia de copias y los mayores ingresos de La mala educación, el rendimiento por copia de este título más que duplicó el de Los abrazos rotos.

Similares cifras nos encontramos si realizamos un análisis comparativo entre este filme y el primero que realizó Almodóvar la pasada década, Hable con ella. 
Tal como se puede ver en el tercer cuadro, al igual que sucedió con La mala educación, Hable con ella superó los seis millones de euros de recaudación consiguiendo, por tanto, una recaudación superior de algo más de dos millones de euros que Los abrazos rotos. En cuanto al número de espectadores, la diferencia es aún mayor, ya que Hable con ella casi duplica a la película objeto de análisis en este monográfico.

\begin{tabular}{|c|c|c|}
\hline \multicolumn{3}{|l|}{ Cuadro $\mathrm{n}^{\circ} 3$} \\
\hline \multicolumn{3}{|c|}{$\begin{array}{c}\text { ANÁLISIS COMPARATIVO } \\
\text { RECAUDACIÓN EN TAQUILLA ESPAÑA } \\
\text { HABLE CON ELLA / LOS ABRAZOS ROTOS }\end{array}$} \\
\hline TÍTULO & HABLE CON ELLA & $\begin{array}{c}\text { LOS ABRAZOS } \\
\text { ROTOS }\end{array}$ \\
\hline Fecha de estreno en España & $15 / 03 / 2002$ & 18/03/2009 \\
\hline Recaudación total en España & $€ 6.208 .691,42$ & $€ 4.172 .843,54$ \\
\hline Número de espectadores total en España & 1.367 .450 & 696.622 \\
\hline
\end{tabular}

Por último, si realizamos un análisis comparativo entre Los abrazos rotos y la siguiente (y última) producción de Almodóvar, La piel que habito, de nuevo podemos comprobar cómo las cifras de Los abrazos rotos siguen siendo peores, tanto en recaudación, como en asistencia de espectadores. Así, aunque no alcanza, por bastante diferencia, la recaudación de seis millones de euros, como sí habían conseguido las tres películas precedentes, la suma total de la taquilla es de más de 400.00o euros. También fue bastante más lo que recaudó en su primer fin de semana, algo más de 200.00o euros. Sin embargo, donde la diferencia es menor, es en el apartado de espectadores, dado que la diferencia entre ambas es de tan sólo 30.000 asistentes.

Cuadro $\mathrm{n}^{\mathrm{O}} 4$

\begin{tabular}{|c|c|c|}
\hline \multicolumn{3}{|c|}{$\begin{array}{c}\text { ANÁLISIS COMPARATIVO } \\
\text { RECAUDACIÓN EN TAQUILLA ESPAÑA } \\
\text { LOS ABRAZOS ROTOS / LA PIEL QUE HABITO }\end{array}$} \\
\hline TÍTULO & $\begin{array}{c}\text { LOS ABRAZOS } \\
\text { ROTOS }\end{array}$ & $\begin{array}{l}\text { LA PIEL QUE } \\
\text { HABITO }\end{array}$ \\
\hline
\end{tabular}




Fecha de estreno en España
Número de salas en estreno en España
Presupuesto
Recaudación primer fin de semana España
Recaudación total en España
Número de espectadores total en España

\begin{tabular}{|c|c|}
\hline $18 / 03 / 2009$ & $01 / 09 / 2011$ \\
\hline 246 & 287 \\
\hline$€ 15.000 .000$ & $€ 10.000 .000$ \\
\hline$€ 978.046,00$ & $€ 1.207 .937,00$ \\
\hline $64.172 .843,54$ & $€ 4.604 .903,78$ \\
\hline 696.622 & 726.713 \\
\hline
\end{tabular}

Datos del Ministerio de Cultura

\section{Razones de este fracaso comercial}

Realizado este análisis comparativo con cada una de las películas de Pedro Almodóvar estrenadas desde la pasada década, podemos colegir que Los abrazos rotos ha supuesto su mayor fracaso comercial: ha obtenido menos ingresos en términos absolutos y en proporción al número de copias en su lanzamiento, ha tenido las peores cifras de taquilla en el primer fin de semana y es la que ha sido vista por un menor número de espectadores. Siendo todos ellos datos negativos, hemos de añadir que todo ello coincide además en la producción de mayor presupuesto de las realizadas hasta el momento por Pedro Almodóvar.

¿Cuáles han podido ser las razones de este fracaso económico en España? ¿Qué factores pudieron influir en que esta, a priori, atractiva propuesta de Almodóvar no lograra suscitar el interés del público, siendo, además, su regreso al cine tras el gran éxito de Volver?

Son varios los aspectos que hay que analizar en este sentido y que siempre están presentes cuando se estudia el lanzamiento de una película. El primero es la elección del día en que la película comienza su andadura comercial, tal como señala Jaime Fuertes:

"Todo el trabajo de diseño de promoción de un proyecto va encaminado hacia una de las decisiones más peliagudas de todo el proceso: elegir una buena fecha de estreno" (Fuertes, 2008: 45).

En la industria del cine es habitual que producciones de este calibre tengan ya este día establecido antes de comenzar siquiera el rodaje. Es el caso de la distribuidora Warner Spain que puede llegar a anticipar el estreno de una película con un año y medio de antelación, cuando ésta no deja de ser un proyecto, del que sólo se anticipa el nombre del director y la productora, porque 
se desconoce incluso quiénes formarán el elenco protagonista. En cuanto a la fecha, Almodóvar, es un director que se deja llevar más por la tradición y por cuestiones personales, al menos en el período analizado, que por un estricto criterio profesional. Salvo La piel que habito, las otras cuatro películas que ha rodado en los últimos doce años se han estrenado siempre en las mismas fechas, a mediados de marzo (con un margen de cuatro días, entre el 15 y el 18). No debe entenderse este detalle como un capricho exclusivo de Almodóvar porque se da con cierta frecuencia en directores con el poder y la capacidad de poder elegir la fecha de estreno (potestad de la que carecen la inmensa mayoría de los directores). Así, por citar sólo a dos directores de renombre, Fernando Trueba y Santiago Segura, coinciden con el cineasta manchego en mostrar, título a título, su preferencia por una fecha en concreto: principios de diciembre en el caso de Trueba y al igual que Almodóvar, en marzo, en el caso de Segura. Para los tres directores se trata de una cuestión supersticiosa; los buenos resultados que cosecharon con alguna película (Belle epoque y Torrente 1) les lleva a querer estrenar los siguientes trabajos en la misma fecha. Es de señalar que tras el fracaso de Los abrazos rotos, Almodóvar rompió con la tradición de estrenar a mediados de marzo y La piel que habito se estrenó en España el primer día de septiembre. Ejemplo de este carácter supersticioso lo encontramos en un artículo de Sara Brito en Público cuando la periodista recoge un fragmento del blog de Almodóvar la noche en que está pendiente de conocer los datos de recaudación del primer fin de semana de La piel que habito, mientras ve en televisión un partido de Nadal en el US Open:

"Si gana Nadal la taquilla se portará bien con La piel que habito. Si pierde... No quiero ni pensarlo" (Brito, 2011).

Nadal ganó y la recaudación superó a la del primer fin de semana de Los abrazos rotos.

La importancia de la elección del día no se debe exclusivamente a la elección de una fecha idónea según las características de la película (un título destinado a un público infantil siempre preferentemente en vacaciones escolares, por ejemplo), sino que también está condicionado por qué otras películas se estrenan ese mismo día. Tal como recoge Fuertes:

En Estados Unidos [...] si dos películas que buscan el mismo público deciden estrenar en el mismo día, acaban recurriendo a un árbitro para decidir cuál de ellas cambiará su fecha de estreno. [...] El 
encargado del arbitraje es una empresa de investigación de mercados llamada National Research Group (NRG)" (Fuertes, 2008: 48).

Cuando dos películas eligen un mismo día recurren a esta entidad que, de acuerdo con un informe semanal que elabora sobre preferencias del público, determina cuál de los dos títulos tiene menos posibilidades para que busque una fecha alternativa. Fue el caso de La guerra de los mundos, Batman begins y Los cuatro fantásticos, que eligieron la codiciada fecha del 4 de julio de 2005. La película de Spielberg fue la afortunada mientras que la nueva entrega de Batman se adelantó dos semanas y la tercera se retrasó cuatro días.

"Las tres vencieron en la taquilla de sus respectivos fines de semana. La NRG evitó una vez más un descalabro económico e hizo ganar millones de dólares a cada uno de los tres estudios implicados" (Fuertes, 2008: 49).

En España no existe ninguna institución similar u organismo con una función de arbitraje en una situación como ésta, de modo que en el caso de Los abrazos rotos, Almodóvar, al confirmar su preferencia por estrenar a mediados de marzo, no tuvo en cuenta qué títulos tenían previsto su estreno en la misma fecha o en la semana inmediatamente anterior y posterior. De las estrenadas simultáneamente tan sólo dos producciones más, la comedia romántica Pareja de tres y la cinta de espías y humor Duplicity se situaron entre las diez primeras en recaudación ese primer fin de semana. Ninguna de las dos contaba con un público similar al de Los abrazos rotos, por lo que no cabía competencia con otros títulos relevantes. Con lo que no contaban era con entrar en la primera semana en segunda posición por culpa de una película que en su tercera semana de explotación seguía liderando el ranking, Gran Torino, de Clint Eastwood. Aunque ambos directores comparten un público adulto que suele acudir al cine con una frecuencia mensual o en ocasiones especiales de películas "must see" (Brunet, 2009), los datos fueron decepcionantes porque no se esperaba que Almodóvar pudiera sucumbir ante la película de Eastwood en su tercera semana en cartel. Considerada como un "sleeper" (modesta película que alcanza un éxito comercial inesperado), Gran Torino se benefició de las favorables opiniones que transmitían sus espectadores. De hecho, en la siguiente semana las diferencias con la película de Eastwood aumentaron. Mientras que los ingresos en taquilla de la cinta de Almodóvar eran un 32\% inferiores a la semana precedente, en el caso de Eastwood, eran tan sólo de un 9\%, según datos de Box Office.es. En 
cualquier caso, la lista de películas más comerciales eran liderada esta semana por otra producción española, Mentiras y gordas, que lograba en una semana casi el triple que Los abrazos rotos en dos (algo más de un 1.800.00o euros frente a 670.000 euros).

Otro factor que pudo influir en el rendimiento económico del filme de Almodóvar fue la mala acogida que recibió por parte de la crítica. La relación entre la crítica de cine y el director ha sido singular. A lo largo de su carrera fueron varias las ocasiones en que Almodóvar realizó comentarios irónicos, mordaces o sarcásticos:

"A un crítico le montaría un piso, pero con condiciones. Previamente me aseguraría de que el piso estuviera endemoniado para que por fin le ocurrieran cosas en su vida" (Deubi, 1986, sin numerar).

En otra entrevista expresaba su opinión de un modo más contundente:

"La crítica es un género que me da miedo y me parece muy triste. Ver cosas toda la vida para criticarlas luego es un destino bastante amuermante. Como decía Boadella, los críticos son parásitos de lo que hacen los demás. Y a un parásito es difícil respetarle, ¿no? Y nadie respeta a un parásito a menos que esté locamente enamorado de ellos, y yo no estoy enamorado de ningún crítico" (Boquerini, 1989: 126).

En cualquier caso, puede sorprender la opinión negativa del director sobre la crítica si tenemos en cuenta el dato que proporciona Holguín en su libro sobre Almodóvar:

"La lluvia de críticas en todo el mundo ha sido enorme, de las cuales el 90 por 100 son positivas" (Holguín, 1994: 23).

Con motivo del estreno de Los abrazos rotos se desató una polémica especialmente dolorosa entre el crítico de cine de El País, Carlos Boyero y el cineasta, que alcanzó bastante notoriedad y que, en gran parte, pudo perjudicar la explotación comercial de Los abrazos rotos. Boyero recurrió al título de una célebre película de Almodóvar para el enunciado de su crítica, ¿Qué he hecho yo para merecer esto?, que concluía del siguiente modo:

"Y no te crees nada, aunque el envoltorio del vacío intente ser solemne y de diseño. Y los intérpretes están inanes o lamentables. La única sensación que permanece de principio a fin es la del tedio. Y dices: todo esto, ¿̇para qué?” (Boyero, 2009).

Almodóvar decidió no permanecer en silencio y a través de su blog personal descalificó a Carlos Boyero por no haber escrito una crítica de cine: 
"Un hombre que emplea el 75 por ciento del espacio para despotricar sobre mi persona (lo que ni siquiera es una novedad, porque lleva casi treinta años haciéndolo), y alrededor del 25 por ciento para despachar la película diciendo cosas como que la interpretación de los actores es "inane y lamentable" (dos de sus adjetivos favoritos) sin mostrar un sólo ejemplo que nos ayude a entenderle... Un texto en el que casi no habla de la película y por supuesto no aporta la más mínima razón en la que basar el tedio infinito que le provoca... Un texto así no es una crítica. Es una no-crítica” (Almodóvar, 2009).

Desatada la polémica, a ella tampoco fue ajena el propio Comité de Redacción de El País que ponía el acento justamente en toda la campaña de promoción que este diario había difundido con motivo del estreno.

“Olvida Almodóvar mencionar la cantidad de páginas que se han dedicado antes del estreno a su película, Los abrazos rotos. Desde El País Semanal y las páginas de Cultura, la información y los despliegues que se le han dedicado no le han debido parecer suficientes. Tampoco los artículos elogiosos que le han brindado Gustavo Martín Garzo y otros columnistas y colaboradores" (Comité de Redacción de El País, 2011).

Además, unos meses antes este mismo diario había realizado una promoción con la colección de las películas dirigidas por Almodóvar en dvd mientras que en Los abrazos rotos son varias las menciones a este periódico, de modo que diario y cineasta se recurrían a la promoción mutua. Precisamente a este aspecto, entre otros muchos, hacía referencia Almódovar, de nuevo en su blog, al replicar al Comité de Redacción de El País:

“También hemos colaborado en la nueva etapa de elpais.com. Hemos llegado a producir materiales audiovisuales exclusivos para que figuraran colgados en su web. ¿Que esta inversión nos interesaba como material promocional? Por supuesto. Y también se beneficiaba el periódico de ello" (Almodóvar, 2009).

La prestigiosa publicación francesa Cahiers du Cinéma es la que más ha profundizado en las, a veces, tormentosas relaciones entre críticos de cine y directores. En el volumen Teoría y crítica del cine, compilación de artículos publicados en la revista a lo largo de cincuenta años se recoge un conflicto similar analizado por Charles Tesson, que concluye así:

“No extrañará que, sobre ese punto, la polémica, muy mal formulada (el ego de autor herido y no la reivindicación artesanal de un savoirfaire honorable, sobre el cual nos gustaría ser juzgados sin ser automáticamente descalificados), se haya transformado en un diálogo de sordos, propicio a que viejas ideas, bastante convencionales, sobre el papel necesario de la crítica, vuelvan a 
adquirir carta de naturaleza" (Antoine de Baecque, compilador, 2005: 352).

De no ser porque corresponde al número 542 de Cahiers du Cinéma de enero de 2000, podría afirmarse que está escrito a propósito del conflicto entre Almodóvar y Boyero. En el mismo volumen Serge Toubiana reflexiona sobre la función de la crítica y su posible influencia en el público frente a las multitudinarias campañas de marketing que acompañan las películas de Almodóvar, por ejemplo.

“Cuanto más funciona la publicidad basándose en la seducción, en la atracción por el merchandising de la película, menos el discurso de la culpabilidad, que es el discurso fundamental de la crítica, puede operar sobre el público" (Antoine de Baecque, compilador, 2005: $321)$.

Sobre el consumo mayoritario por parte del público es interesante la referencia a Pierre Bourdieu que realiza Sassatelli a propósito de los gustos de la denominada por él "clase dominante", en la que bien podría encuadrarse el público potencial del cine de Almodóvar de acuerdo con la siguiente enumeración que realiza:

"Preferían Le Monde a un diario popular, la cocina china a los picnics, ir a un festival de música de vanguardia en vez de escuchar música ligera tradicional, el pop art de Warhol en lugar del virtuosismo de los impresionistas" (Sassatelli, 2004: 137).

Además de la polémica a propósito de la crítica, también debió de influir la duración de la película. No sólo tiene Los abrazos rotos la mayor duración de todas las películas de Almodóvar sino que al alcanzar los 130 minutos, el número de sesiones que se puede proyectar cada día disminuye y por consiguiente son menos los espectadores que pueden verla en un mismo día. Es significativo el dato de la duración porque hasta el título precedente, (con 125 minutos), nunca una película de Almodóvar había sobrepasado las dos horas de duración. De hecho la duración media de su cine es de 107 minutos, con dos de sus películas más significativas, Pepi, Luci, Bom y otras chicas del montón y Mujeres al borde de un ataque de nervios, con una duración inferior e igual, respectivamente, a la hora y media. Analizando las duraciones de sus última cinco películas tanto en España como Estados Unidos se observa que no siempre coinciden. Así, por ejemplo, en la versión americana de Volver hay 14 minutos menos que en la española, pero esta diferencia es aún mayor en Los 
abrazos rotos ya que de los 130 minutos de la versión estrenada en España se pasó a los 105’ que vieron en Estados Unidos, 25 minutos que suponen casi una quinta parte de la película. Otro dato significativo es que la versión de Los abrazos rotos comercializada en España en dvd tiene una duración de 120 minutos. Ambos detalles pueden apuntar a que el propio director recapacitara sobre la adecuada duración que debía tener la película y a que comprendiera que su excesiva duración pudo ser uno de los factores que contribuyó a que el filme no tuviera una mejor acogida entre el público.

\section{Fracaso comercial fuera de España}

Enumerados los posibles motivos de este fracaso comercial analizamos ahora cómo fue el rendimiento en la taquilla en otros mercados importantes para el cine de Pedro Almodóvar: Francia y Estados Unidos.

Como se puede ver en el cuadro número 5, en Francia Los abrazos rotos consiguió casi una tercera parte menos que Volver y un 25\% menos que Hable con ella, pero sin embargo, su recaudación sí superó en casi 300.000 dólares a la de La mala educación y en algo más de 1.200.000 dólares a la de La piel que habito, el título con menos taquilla de las cinco últimas estrenadas en Francia.

\section{Cuadro $n^{0} 5$}

\section{RECAUDACIÓN EN TAQUILLA FRANCIA}

\begin{tabular}{|l|c|}
\hline TÍTULO & RECAUDACIÓN \\
\hline HABLE CON ELLA & $9.264 .928 \$$ \\
\hline LA MALA EDUCACIÓN & $6.649 .775 \$$ \\
\hline VOLVER & $17.010 .675 \$$ \\
\hline LOS ABRAZOS ROTOS & $6.936 .672 \$$ \\
\hline LA PIEL QUE HABITO & $5.729 .704 \$$ \\
\hline Datos de Box Office Mojo & \\
\hline
\end{tabular}

Podemos observar en el cuadro número 6 que en Estados Unidos hay unas cifras similares a las de Francia, prácticamente en la misma proporción, que confirman el fracaso de Los abrazos rotos, especialmente si se compara su 
rendimiento con el de Volver. En cualquier caso, el público norteamericano se mostró de un modo menos entusiasta que el francés y no se da la misma diferencia que en el país vecino entre ambos títulos. La recaudación de Hable con ella es prácticamente la misma en los dos países, mientras que La mala educación tuvo un mejor rendimiento que Los abrazos rotos en Estados Unidos al revés de lo que sucedió en Francia.

En ambos países el desplome en la taquilla de Los abrazos rotos alcanza también al siguiente título, La piel que habito, donde a diferencia de lo que ocurría en España logra un menor ingreso en taquilla. Mientras que en Francia, como ya se vio, la diferencia entre ambos títulos fue de casi 1.200.00o dólares, en Estados Unidos, fue un 50\% superior: es decir, más de 1.800.000 dólares. Por el contrario, en España La piel que habito recaudó más del 10\% que Los abrazos rotos, lo que confirmaría el hecho de que fue en España donde más fracasó esta película.

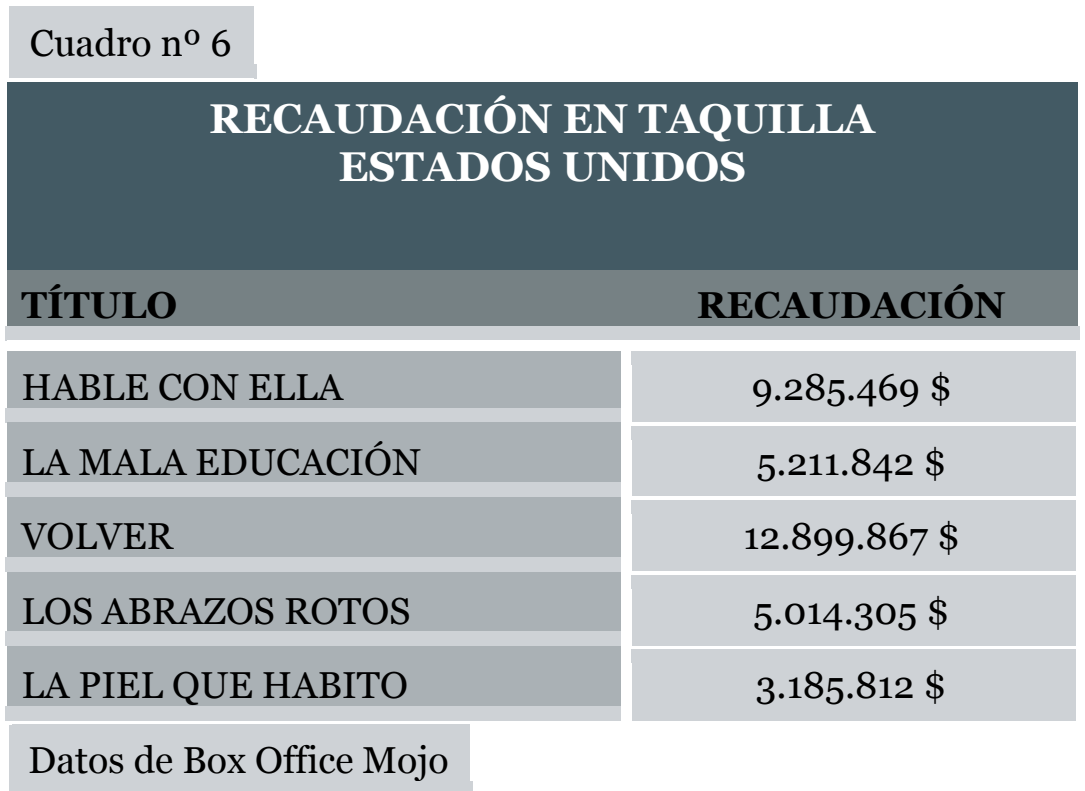

Por último, si analizamos en el cuadro número 7 la recaudación total de las últimas cinco películas de Pedro Almodóvar se confirma que el mayor éxito mundial en esta última etapa del cineasta manchego es Volver, estrenada comercialmente en 41 países y con una recaudación que duplica la del título precedente, La mala educación y casi triplica la del siguiente título, Los abrazos rotos.

En cuanto al número de países donde cada una de estas producciones se ha estrenado en salas es significativo que La mala educación haya obtenido 
menores ingresos en taquilla que Hable con ella a pesar de haber llegado a más países. De nuevo encontramos que la temática que afrontaba este film bien pudo provocar el rechazo entre algunos sectores del público y en algunos países. También es de destacar que, a excepción de Hable con ella, Los abrazos rotos es el único de estos títulos que se ha estrenado en menos de treinta países, doce menos que Volver y nueve menos que La piel que habito.

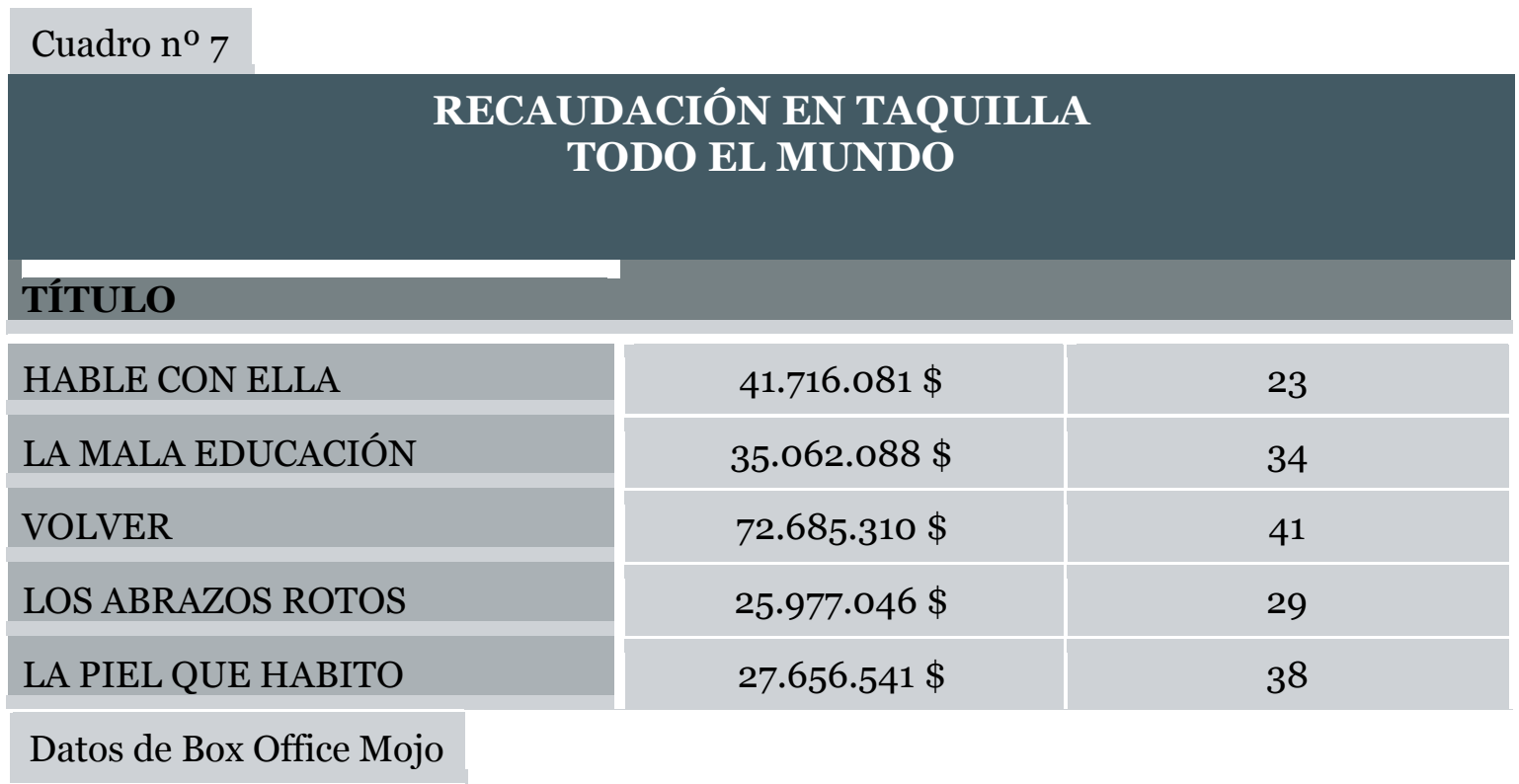

\section{Referencias bibliográficas}

ALMODÓVAR, Pedro (2009). Blog Pedro Almodóvar: "Notas sobre Crónica negra del Festival de cine de Cannes”. http://www.pedroalmodovar.es/ PABES_11_T.asp [Consultado 17/07/2012]

ALMODÓVAR, Pedro (2009). Blog Pedro Almodóvar: "Notas sobre Segunda Crónica, Respuesta a El País". http://www.pedroalmodovar.es/ PABES 12 T.asp [Consultado 17/07/2012]

BEJARANO, Antonio y HERMOSO, Borja (2004). "Enrique González Macho rompe con Warner y retira de todos sus cines La mala educación. En El Mundo, 1 de abril de 2004.

BOQUERINI (1989). Pedro Almodóvar. Madrid: Ediciones JC.

BOYERO, Carlos (2009). “¿Qué he hecho yo para merecer esto?” En El País, 18 de marzo de 2009

BRITO, Sara (2011). “Almodóvar recupera la confianza tras el roto de "Los abrazos”. En Público, 6 de septiembre de 2011.

BRUNET, Pau (2009). "Clint rompe con los abrazos de Pedro". http://www.eleconomista.es/boxoffice/reports spain/2009/clintrompelos-abrazos-de-pedro/ [Consultado 16/07/2012] 
DE BAECQUE, Antoine (2005). Teoría y crítica del cine, avatares de una cinefilia. Barcelona. Ediciones Paidós Ibérica.

DEUBI, David (1986). No se lo digas a nadie. Muestra Cinematográfica del Atlántico, Alcances. Cádiz.

FUERTES, Jaime (2008). Un negocio de cine. Sevilla: Editorial Almuzara

HOlguín, Antonio (2006). Pedro Almodóvar. Madrid: Ediciones Cátedra (Grupo Anaya).

SASSATELLI, Roberta (2004). Consumo, cultura y sociedad. Madrid: Amorrortu editores.

STRAUSS, Frédéric (1995). Pedro Almodóvar, un cine visceral. Madrid: El País Aguilar.

VÁZQUEZ VARELA, Carmen y ZURIÁN, Fran A. (coordinadores) (2005). Almodóvar: el cine como pasión. Actas del Congreso Internacional "Pedro Almodóvar". Cuenca: Ediciones de la Universidad de Castilla-La Mancha.

VIDAL, Nuria (1988). El cine de Pedro Almodóvar. Madrid: Instituto de la Cinematografía y las Artes Audiovisuales. 